\title{
A Descriptive Correlational Study Measuring the Emotional Impact of ACL Injury and Reconstruction on Intention to Return and Actual Return to Previous Level of Sport in Competitive Athletes
}

\author{
Moriah M. Frazee \\ CedarvilleUniversity, mfrazee@cedarville.edu \\ Molly M. Frazee \\ CedarvilleUniversity,mmfrazee@cedarville.edu
}

Follow this and additional works at: http://digitalcommons.cedarville.edu/nursing theses

Part of the Medicine and Health Sciences Commons

\section{Recommended Citation}

Frazee, Moriah M. and Frazee, Molly M., "A Descriptive Correlational Study Measuring the Emotional Impact of ACL Injury and Reconstruction on Intention to Return and Actual Return to Previous Level of Sport in Competitive Athletes" (2015). Master of Science in Nursing Theses. 14.

http://digitalcommons.cedarville.edu/nursing_theses/14

This Thesis is brought to you for free and open access by DigitalCommons@Cedarville, a service of the Centennial Library. It has been accepted for inclusion in Master of Science in Nursing Theses by an authorized administrator of DigitalCommons@Cedarville. For more information, please contact digitalcommons@cedarville.edu. 


\title{
A DESCRIPTIVE CORRELATIONAL STUDY MEASURING THE EMOTIONAL IMPACT OF ACL INJURY AND RECONSTRUCTION ON INTENTION TO RETURN AND ACTUAL RETURN TO PREVIOUS LEVEL OF SPORT IN COMPETITIVE ATHLETES
}

\author{
A thesis submitted in partial fulfillment \\ of the requirements for the degree of \\ Master of Science in Nursing
}

By

MOLLY MARIE FRAZEE AND MORIAH MAE FRAZEE

B.S.N. Liberty University 2009

2015

Cedarville University 


\begin{abstract}
BACKGROUND: Anterior Cruciate Ligament (ACL) injuries among athletes are increasingly common, yet less than $50 \%$ of these athletes return to their previous level of sport participation. While most of these athletes are physically ready to return to sport, many of them have reported they were not emotionally ready to return.

PURPOSE: The purpose of this study was to determine the relationship between 1) the emotional readiness to return to sport, 2) intention to return to their previous level of sport participation, and 3) actual return to their previous level of sport participation after ACL injury and reconstruction in competitive adult athletes.
\end{abstract}

METHODS: This was a descriptive correlational study with a convenience sample of 64 athletes recruited through Facebook and email. The variables of interest were measured using the ACL-Return to Sport Index (ACL-RSI), and questions regarding an athlete's intention to and actual return to their previous level of sport participation.

RESULTS: Athletes who intended to return to their previous level of sport participation were 11 times more likely to return to sport than athletes with no intention to return to sport $(\mathrm{p}=.002)$. Athletes who scored greater than 5 (0-10) on the ACL-RSI were 7 times more likely to intend to return to their previous level of sport participation $(\mathrm{p}=.01)$ but only 2.5 times more likely to actually return to their previous level of sport participation $(\mathrm{p}=.22)$.

CONCLUSION: This study showed an athlete's intention to return to sport does in fact impact their actual return to previous level of sport after ACL injury and reconstruction, though they should be interpreted cautiously due to the small sample size. Through further research the ACL-RSI scale may be used to predict an athlete's ability to return to the previous level of sport. 


\section{Table of Contents}

Page

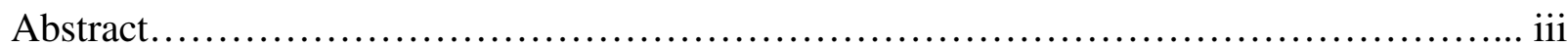

Chapters:

1. Introduction and Literature Review..............................................

2. Theoretical Framework.............................................................

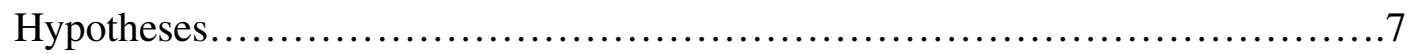

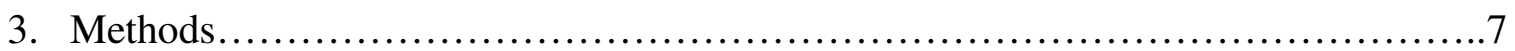

Subjects and Data Collection...............................................

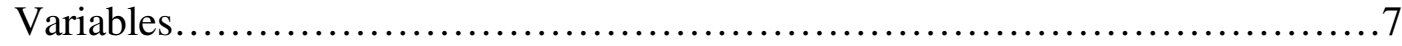

Data Analysis........................................................... 9

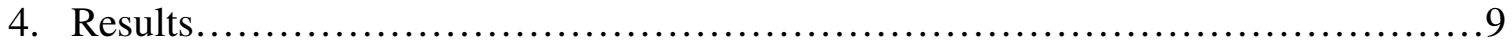

Demographics............................................................

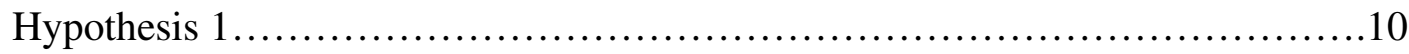

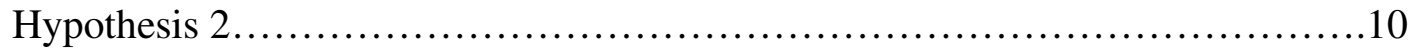

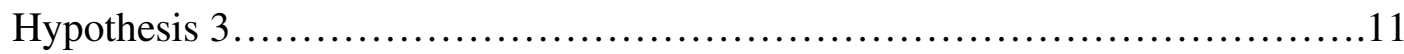

Summary of Relationships...................................................11

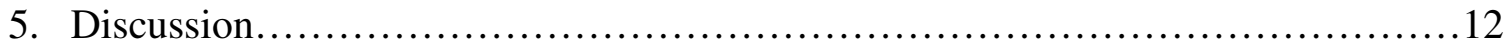

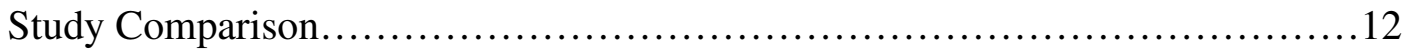

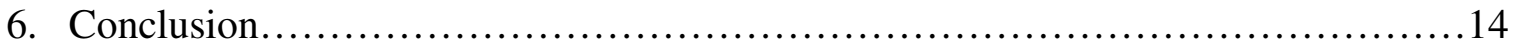

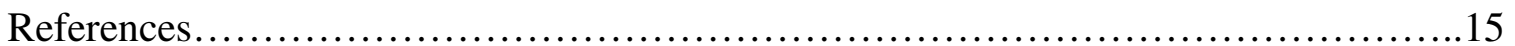

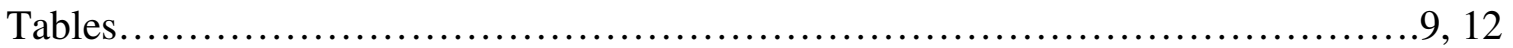

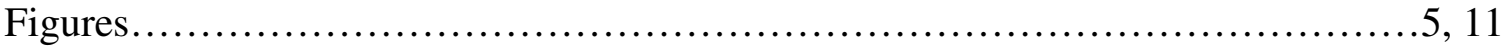

Appendices............................................................ 29, 21 
A. Permission from Dr. Kate Webster to use the ACL-RSI scale.................19

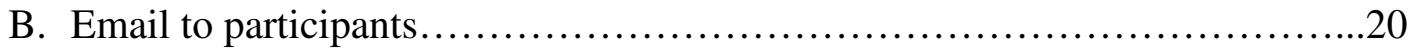

C. Survey sent to participants........................................21 


\section{Introduction}

ACL injuries have both immediate and long-term consequences for athletes. Over two million anterior cruciate ligament (ACL) injuries occur worldwide annually (Samuelsson, 2012). Treatment costs related to surgery, therapy, and rehabilitation are substantial. It has also been well documented that regardless of whether the ACL is reconstructed, those with an ACL injury are at a 10-fold higher risk of developing early-onset degenerative knee osteoarthritis compared with the non-injured population (Fleming, 2003). This long-term perspective demonstrates the tremendous societal economic impact of ACL tears. The cost to society ranges from $\$ 8$ billion to $\$ 18$ billion annually (Porucznik, 2013). This cost includes the surgical repair of the ACL and the rehabilitation following the surgical repair, which allows an individual to return to a more functional, pain-free lifestyle.

ACL injuries are not only costly from financial and healthcare perspectives, but they also have an emotional impact on the athlete. In 2010, researchers reported that athletes work hard to overcome the emotional consequences of their ACL injury (Olofsson, et. al, 2010). These include: feelings of loss, physical dependency on others, fear of re-injury, lack of selfconfidence, and mood swings (Olofsson, et. al, 2010.) In fact, another researcher has reported that twelve months post-operatively athletes still considered themselves injured (Mainwaring, 1999). Understanding the emotional impact this type of injury has on an athlete will help health care professionals meet the needs of this patient population not only physically, but also emotionally, in order to ensure a better recovery.

\section{Literature Review}

Understanding the emotional impact an ACL injury can have on an athlete is an essential component for healthcare providers to address in order to properly evaluate their patients' 
recovery process. Several studies have been conducted to determine the characteristics of ACL injury events (Boden, Dean, Feagin, \& Garrett, 2000; Krosshaug et al., 2007; Agel, PalmieriSmith, Dick, Wojtys, \& Marshall, 2007), identify risk factors for ACL injury (Simon, Everhart, Nagaraja, \& Chaudhari, 2010; Stijak, Herzog, \& Schai, 2008), and develop prevention strategies (Myer, Ford, Brent, and Hewett, 2006; Peterson, J., \& Peterson, E., 2012), while fewer research studies have been conducted to understand the emotional impact an ACL injury has on an athlete planning to return to sport. This is important because studies have shown up to $50 \%$ of athletes do not return to their previous level of participation in their sport after standard ACL reconstruction and rehabilitation (Feller \& Webster, 2003; Kvist, Ek, Sporrstedt, \& Good, 2005). A study conducted by Arden, Webster, Taylor, \& Feller (2011), showed that $85-90 \%$ of patients reported satisfactory knee function after ACL reconstruction, but less than half were able to return to their previous sport participation. Furthermore, these authors reported that $82 \%$ of patients with an ACL injury participated in some kind of sport following their ACL injury, while only $63 \%$ had returned to their pre-injury level of participation, and only $44 \%$ returned to competitive sport at their final follow-up (Arden et al., 2011).

While many authors do not report the reasons injured athletes do not return to their sport, those who do are relatively unanimous in their findings. In 2005, researchers from Sweden surveyed 62 athletes following ACL reconstruction, and found that of the $47 \%$ who did not return to their previous level of participation in their sport, $24 \%$ reported fear of re-injury as the reason (Kvist et. al.). In 2007 and 2009 these findings were confirmed by researchers from Canada (Tripp et. al.) and Australia (Langford, Webster, \& Feller). Furthermore, physical readiness to return to sport does not equate with mental readiness to return to sport, and when an 
athlete returns to their previous level of participation in sport after injury, their confidence is significantly lower (Podlog \& Eklund, 2007; Johnston \& Carroll, 1998).

Several scales have been used to examine emotional factors associated with ACL injury and reconstruction. These include the Emotional Responses of Athletes to Injury Questionnaire, which measures 12 common emotions an injured athlete may experience and ranks the level of emotion on a scale of 0-10 (Langford, Webster, \& Feller, 2008); the Knee-Self Efficacy Scale which measures the individual's confidence in their daily activities, sports and leisure activities, and physical activities with or without reconstruction (Thomee, Wahrborg, Borjesson, Thomee, Eriksson, \& Karlsson, 2006); and the Tampa Scale of Kinesiophobia which measures an individual's fear of pain with movement (Hudes, 2011) However, these scales were not created to explicitly evaluate the emotional impact of returning to sport on an athlete. As a result, in 2008 researchers from Australia (Webster, Feller, \& Lambros) saw a need to develop a tool to measure athletes' emotion, confidence in performance, and risk appraisal in regards to their return to sport. This tool is called the ACL-Return to Sport after Injury Scale (ACL-RSI). Unlike the scales mentioned above, the ACL-RSI has been designed to include responses that are related to returning to sport, such as confidence and risk of re-injury (Webster, Feller, \& Lambros, 2008). The ACL-RSI measures emotions, confidence in performance, and risk appraisal, which are three of the most common psychological responses linked with return to sport (Webster, Feller, \& Lambros, 2008).

In 2013, researchers (Kvist, Österberg, Gauffin, Tagesson, Webster, \& Ardern) compared the mean score of the ACL-RSI scale of athletes who did return to the same activity level after ACL injury and reconstruction with athletes who did not return to the previous level of sport after ACL injury and reconstruction. The mean score of athletes who returned to their previous 
level of sport after ACL injury and reconstruction was $7.0(0-10)$, while the mean score of athletes who did not return to their previous level of sport was 4.3 ( $\mathrm{p}<.001)$ (Kvist et. al, 2013).

While the ACL-RSI is relatively new, its creators and others have suggested ways it can be utilized in future research. First, comparing the emotional impact of a second ACL injury compared to the emotional impact of a first ACL injury should be investigated (Webster et al., 2008). Second, the effects of gender, level of previous sport participation (i.e. elite vs. nonelite) warrants investigation (Langford, 2009). Finally, longitudinal studies should be conducted to determine the relationship between the score on the ACL-RSI and an athletes' success at returning to sport (Webster et al., 2008).

Therefore, the purpose of this study was to determine the relationship between 1) the emotional readiness to return to sport, 2) intention to return to their previous level of sport participation, and 3) their actual return to their previous level of sport participation after ACL injury and reconstruction in competitive adult athletes.

\section{Theoretical Framework}

This theoretical framework was developed based on a review of the theoretical and scientific literature, and included the hypothesized relationships between the key variables: competitive athlete; ACL injury with surgical repair; emotional impact of ACL injury and repair; and an athlete's intention to return to the sport that caused their injury. The theoretical underpinnings of the current study are similar to that of Kvist et. al (2013) with one exception: we added the variable of intention to return to sport. (Figure 1). The other concepts were all included in work previously published (Kvist et al., 2013). 


\section{Figure 1: Hypothesized theoretical relationships between key variables}

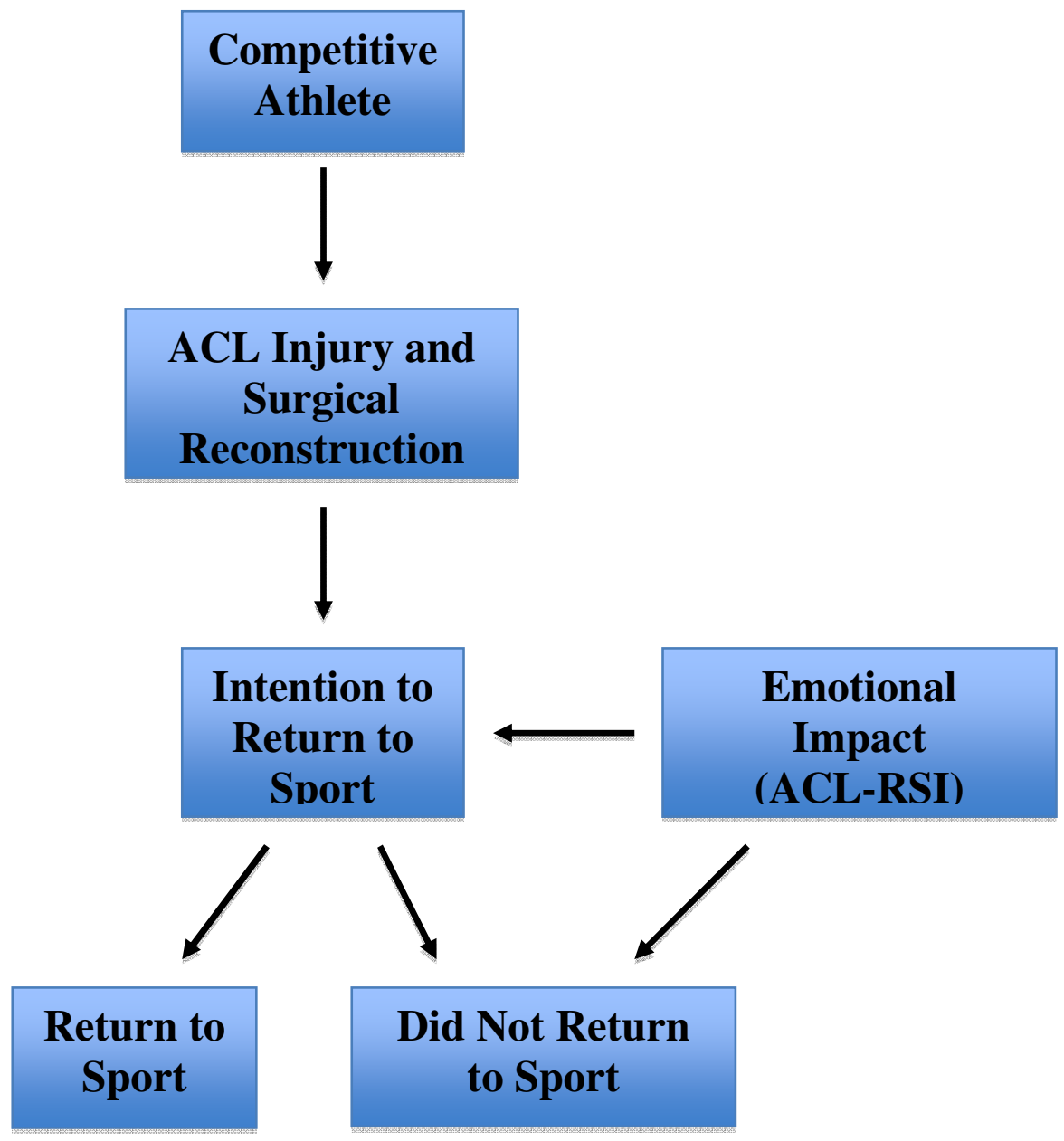

Competitive athlete was defined as a female or male athlete who was part of an organized team sport at the high school, collegiate, professional, or club sport level.

ACL injury was defined as the tearing of the ACL inside an athlete's knee joint (MayoClinic, 2013). The ACL is one of four ligaments critical to the stability of the knee joint (Cluett, 2014). There are two collateral ligaments on either side of the knee and two cruciate ligaments on the inside of the knee that cross one another and form an "X". The ACL runs through the center of the knee joint and prevents hyperextension and hyper-rotation of the knee joint (Quinn, 2014). The ACL can be injured in several ways. This type of injury frequently 
occurs in athletes who play sports that involve direct contact, sudden stops, and/or rapid changes in direction. ACL injuries commonly occur in the following sports: basketball, soccer, football, and volleyball. Symptoms of an ACL injury may include: hearing a "pop" in the knee; experiencing sudden instability of the knee; limited range of motion; and swelling/pain of the injured knee (Fischer \& Campbell, 2014).

Surgical repair of an ACL injury was defined as a successful surgical operation or invasive procedure to reconstruct or repair the ACL. In order to reconstruct the ACL, tissue grafts must be used. The four types of tissue grafts used to reconstruct the ACL are the patellar tendon, hamstring tendon, quadriceps tendon, and a cadaver graft (Fischer \& Campbell, 2014). Surgery to reconstruct the ACL is done arthroscopically and typically takes 60-90 minutes depending on the extent of the damage inside the knee as well as the type of tissue graft that is being used to repair the ACL (Diaz, 2014). After a surgical repair of the ACL, typical recovery time is 4-6 months to fully return to previous level of sport prior to injury, but can be longer depending on the individual (NIH.gov, 2014). An athlete is considered fully functional when swelling has resolved, and full range of motion and near-full strength has been obtained (Diaz, 2014).

For the purpose of this study, the emotional response to ACL injury and repair was labeled emotional impact. This word is widely used in the ACL injury literature and generally refers to fear of re-injury and decreased confidence levels after surgical repair, which can negatively affect an athlete's return to sport after ACL injury (Webster, Feller, \& Lambros, 2008). Other common emotional responses due to injury may include: sadness, feelings of isolation, irritation, lack of motivation, frustration, anger, alterations in appetite, sleep disturbance, and feeling disengaged. 
Return to sport was defined as an athlete undergoing rehabilitation after surgical repair, with the intention of returning to sport. Some athletes with intention of returning to sport may not actually return to sport.

\section{Hypotheses}

Based on this theoretical framework, there were three proposed hypotheses:

1. The ACL-RSI will be a significant predictor of an athlete's intention to return to their previous level of sport participation.

2. The ACL-RSI will be a significant predictor of an athlete's actual return to their previous level of sport participation.

3. An athlete's intention to return to their previous level of sport participation will be a significant predictor of whether or not they actually do.

\section{Methods}

This was a descriptive correlational study approved by the Cedarville University Institutional Review Board.

\section{SUBJECTS \& DATA COLLECTION:}

Subjects were recruited using several forms of media. These included: facebook posting, email, word of mouth, face-to-face conversations, and network sampling. Every potential participant received an email including a description of the study, risks and benefits, and a link to the survey on Qualtrics. There were nine demographic questions and twelve questions on the ACL-RSI scale. Our sample was recruited from a population of current and former athletes.

\section{VARIABLES}

Competitive athlete was measured by asking the subject the level of participation in his/her sport before the ACL injury. 
ACL injury with surgical repair was measured by asking participants if they had ever torn their ACL and undergone surgical repair in question one of the survey. If they responded "no" they did not receive the rest of the survey.

The emotional impact of ACL injury and repair was operationally defined as the score on the ACL-RSI scale. The ACL-RSI scale consists of a twelve-question survey. Questions one through five focused on the emotional impact of an ACL injury. Questions six through ten focused on confidence in performance and one's ability to return to sport. Questions ten and eleven focused on risk appraisal, which includes fear of re-injury. The answers to the 12-item questionnaire were measured by a sliding scale, with a 0-100 range. The scale is scored by adding all of the individual items and dividing by twelve. Higher scores indicate better emotional readiness. After all our data was collected, we chose to divide the final score by 100 , resulting in an average score between $0-10$, in order to compare and contrast our findings with published research. The ACL-RSI scale has been found to have good reliability and validity, with high internal consistency (Cronbach's alpha of 0.96), and inter-item correlations (Webster, Feller, \& Lambros, 2008). Furthermore, the original ACL-RSI was written in English, and the Swedish translation has been found to be internally consistent, valid and reliable (Kvist et al, 2013).

An athlete's intention to return to sport was measured by their yes or no answer to the following question: Do you intend to return to your previous level of sport after rehabilitation? We asked athletes who had already completed their rehabilitation program, to reflect back on how they felt during their time in rehabilitation.

An athlete's return to sport was measured by their yes or no answer to the following question: Did you return to your previous level of sport after ACL injury and reconstruction? 


\section{DATA ANAYLSIS}

All data was entered into SPSS version 22 for statistical analysis. Demographic data was analyzed using mean, frequencies, and percentages. A chi-square and odds ratio were used to determine if there was a relationship between the variables of interest. Logistic regression was used to determine whether the ACL-RSI or intention could predict return to sport. We transformed the ACL-RSI into a categorical variable with a score of 5 (out of 10) as the cutoff. This cut-off was based on the mean ACL-RSI scores reported by Kvist et al (2013) which were 4.3 for those who did not return to the same activity level after ACL injury and 7.0 for those who did return to the same level of activity after ACL injury.

\section{Results}

One hundred and five participants clicked on the Qualtrics link to begin the survey. However, after we reviewed the data, there were only 64 participants who reported ACL injury and surgical repair with complete survey data (Table 1).

\section{Table 1: Demographics}

\begin{tabular}{|l|l|}
\hline Variable & $\mathbf{N}=\mathbf{6 4}$ \\
\hline Age & $\overline{\mathbf{X}}=27+/-6$ \\
\hline Gender & $75 \%$ female \\
\hline Number of ACL injuries & $70 \%$ one \\
& $30 \%$ two or more \\
\hline Time since injury & $51.6 \%$ less than 5 years ago \\
\hline Level of Sport Participation & $42 \%$ College \\
& $34 \%$ High School \\
& $5 \%$ Professional \\
\hline
\end{tabular}




\begin{tabular}{|l|l|}
\hline Primary sport of participation before ACL & $53 \%$ Basketball \\
& $25 \%$ Soccer \\
& $6 \%$ Volleyball \\
& $3 \%$ Football \\
\hline Intended to return to previous level of sport & $85 \%$ Yes \\
participation during rehabilitation & $15 \%$ No \\
\hline Actual return to previous level of sport & $85 \%$ Yes \\
participation & $15 \%$ No \\
\hline ACL-RSI score & $\overline{\mathrm{x}}=55.7+/-24$ \\
\hline
\end{tabular}

\section{HYPOTHESIS 1}

The first hypothesis stated that the ACL-RSI score would predict intention of an athlete to return to sport. To test this hypothesis, we ran a logistic regression with actual ACL-RSI as the independent variable, and intention to return as the dependent variable. We found that ACLRSI was not a significant predictor of actual return $(\mathrm{p}=0.08)$.

In order to get a better idea of the relationship between these two variables, we calculated the odds of an athlete actually returning to the previous level of sport participation based on their score on the ACL-RSI. These results showed that an athlete who scored 5 or higher was 7 times more likely to actually return to sport than those who scored less than $5(\mathrm{p}=.01)$.

\section{HYPOTHESIS 2}

The second hypothesis stated that the ACL-RSI score would predict an athlete's actual return to sport. To test this hypothesis, we ran a logistic regression with ACL-RSI as the 
independent variable, and actual return as the dependent variable. We found that ACL-RSI was not a significant predictor of actual return $(\mathrm{p}=0.124)$.

In order to get a better idea of the relationship between these two variables, we calculated the odds of an athlete actually returning to the previous level of sport participation based on their score on the ACL-RSI. These results showed that an athlete who scored 5 or higher was 2.5 times more likely to actually return to sport than those who scored less than $5(\mathrm{p}=.22)$.

\section{HYPOTHESIS 3}

The third hypothesis stated that an athlete's intention to return to sport would predict their actual return to sport. To test this hypothesis, we ran a logistic regression with intention as the dependent variable and the ACL-RSI as the independent variable. We found that intention was a significant predictor of actual return to previous level of sport participation $(p=0.008)$.

Furthermore, athletes who intended to return to their previous level of sport participation were 11 times more likely to return to sport than athletes with no intention to return to sport $(\mathrm{p}=.002)$.

\section{Figure 2: Summary of Relationships}

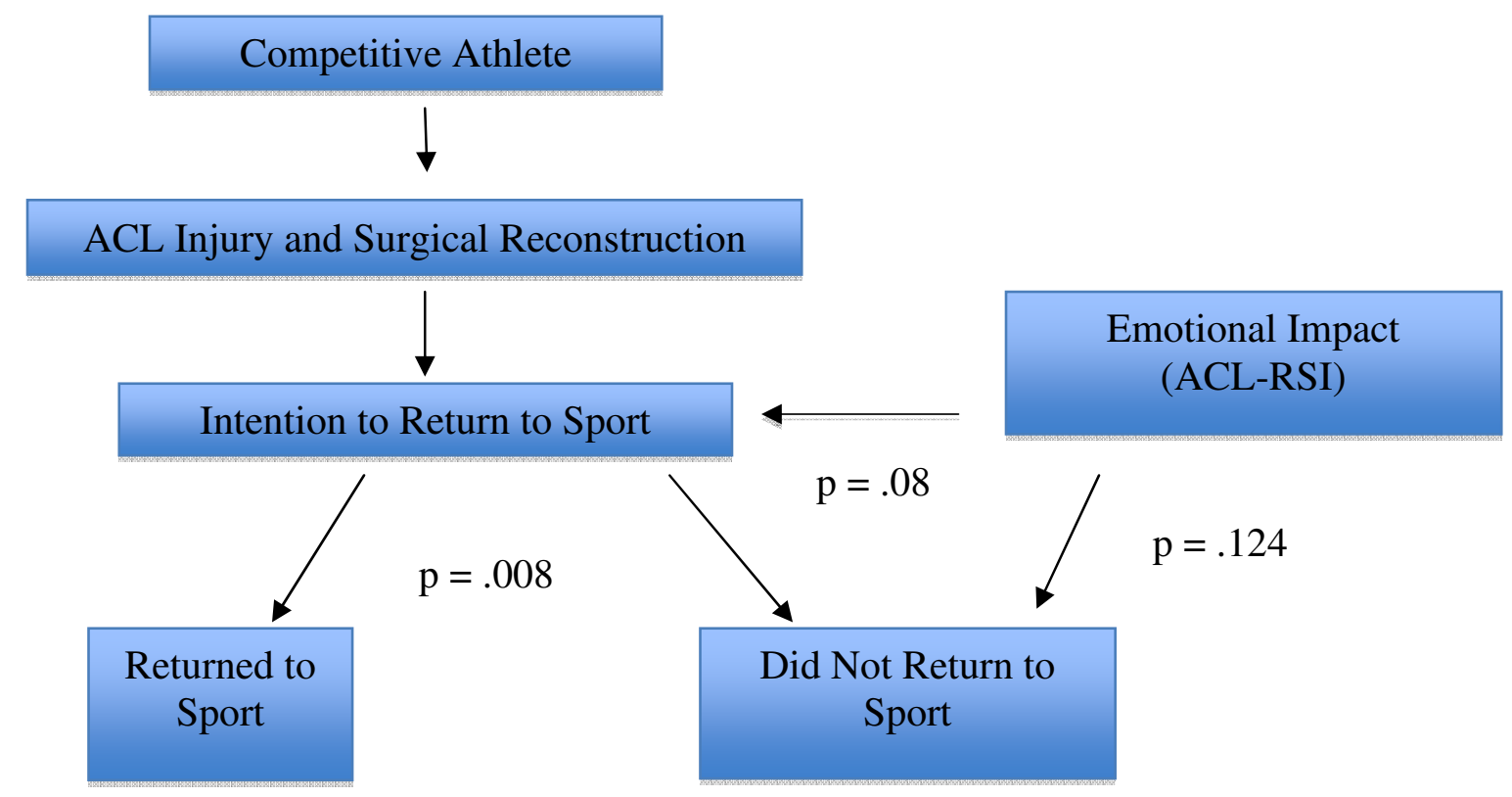




\section{Discussion}

The findings of this study support the hypothesis that an athlete's intention to return to their previous level of sport after ACL injury and reconstruction does in fact predict their actual return. While the ACL-RSI scale was not able to predict intention and/or return, we believe this is in large part a result of low power due to a small sample size $(n=64)$ and an even smaller number of athletes who did not intend to return to their previous level of sport $(\mathrm{n}=9)$. Only $11 \%$ of our sample stated that during their rehabilitation, they did not intend to return to their previous level of sport participation, compared to the $50 \%$ reported in the literature (Feller \& Webster, 2003; Kvist, Ek, Sporrstedt, \& Good, 2005). The past report of significant differences in ACLRSI scores between those who did and did not return to sport, had a sample size of 124 (did not return) and 48 (did return) (Kvist et al., 2013).

Despite our small sample, we were interested to know how the average scores on the ACL-RSI from our population of athletes compared to that of Kvist et al (2013) (Table 2). The mean score on the ACL-RSI of our athletes who did return to their previous level of sport participation was 6.2 compared to 7.0 in the Kvist et al. study (2013). Similarly, our athletes who did not intend to return to their previous level of sport participation scored an average of 4.9 on the ACL-RSI compared to 4.3 in the Kvist et al study (2013). While this difference was not significantly different in the current study $(\mathrm{p}=.129)$, the mean scores between those who did and did not return on the ACL-RSI scale was very similar to those reported by Kvist et al.

\section{Table 2: Study Comparison}

\begin{tabular}{|l|c|c|}
\hline & \multicolumn{1}{|c|}{$\begin{array}{c}\text { Kvist et al } \\
\text { ACL-RSI score }\end{array}$} & $\begin{array}{c}\text { Our study } \\
\text { ACL-RSI score }\end{array}$ \\
\hline $\begin{array}{l}\text { Returned to same } \\
\text { activity level }\end{array}$ & $\mathbf{7 . 0}$ & 6.2 \\
\hline $\begin{array}{l}\text { Did not return to same } \\
\text { activity level }\end{array}$ & 4.3 & 4.9 \\
\hline
\end{tabular}




\begin{tabular}{|l|l|l|}
\hline $\begin{array}{l}\text { Independent sample t- } \\
\text { test significance }\end{array}$ & $\mathbf{p}<.001$ & $* * \mathbf{p}=.129$ \\
\hline
\end{tabular}

This study shows the importance of healthcare providers screening athletes in regards to their intention to return to their previous level of sport after injuring their ACL. One way this screening could occur would be by asking athletes: "Do you intend to return to your previous level of sport after undergoing surgical reconstruction?" If an athlete answers in the affirmative, the healthcare provider could focus on the emotional concerns and fears related to the athlete's return, so that they can achieve their goal.

Nurses routinely use scored survey tools to predict various problems (e.g. the Braden Scale to predict skin breakdown) (Bergstrom, Braden, Laguzza, \& Holman, 1987). We propose that with further study, researchers will find that the ACL-RSI can be used similarly to predict successful rehabilitation and return to sport at previous level. We hypothesized that a score of " 5 " would be able to differentiate between those who did return and did not return to the same activity level after ACL injury and reconstruction, and we did in fact find potential predictive relationships based on this cut-off value.

Based on the results of this study, three suggestions for further research include:

1. Replicate this study with a larger sample size of athletes who have torn their ACL and undergone surgical reconstruction, but have not returned to their previous level of sport.

2. Differences in mean ACL-RSI scores of athletes who have experienced one ACL injury should be compared to the scores of those who have experienced more than one ACL injury.

3. Dichotomize the ACL-RSI at different intervals, to determine which cut-off provides the best predictor of successful return to sport at the previous level of activity. 


\section{Conclusion}

ACL injuries are prevalent among athletes in our world today. While athletes are medically cleared to return to their previous level of sport, less than half return to their previous level of sport. Research shows the emotional impact of an ACL injury and reconstruction plays a large role in an athlete's ability to return to their previous level of sport. This study showed an athlete's intention to return to sport does in fact impact their actual return to previous level of sport after ACL injury and reconstruction, though these conclusions are preliminary due to the small sample size. Through further research, the ACL-RSI scale may be used to predict an athlete's ability to return to the previous level of sport 


\section{References}

ACL reconstruction: MedlinePlus Medical Encyclopedia. (2014). Retrieved from http://www.nl m.nih.gov/medlineplus/ency/article/007208.htm

Agel, J., Palmieri-Smith, R. M., Dick, R., Wojtys, E. M., \& Marshall, S. W. (2007). Descriptive epidemiology of collegiate women's volleyball injuries: National collegiate athletic association injury surveillance system, 1988-1989 through 2003-2004. Journal of Athletic Training, 42(2), 295-302.

Ardern, C. L., Webster, K. E., Taylor, N. F., \& Feller, J. A. (2011). Return to sport following anterior cruciate ligament reconstruction surgery: a systematic review and meta-analysis of the state of play. British Journal Of Sports Medicine, 45(7), 596-606.

Bergstrom, N., Braden, B., Laguzza, A. \& Holman, A. (1987). The Braden Scale for predicting pressure sore risk. Nursing Research. 36(4), 205-210.

Boden, B. P., Dean, G. S., Feagin, J. A., Jr., \& Garrett, W. E., Jr. (2000). Mechanisms of anterior cruciate ligament injury. Orthopedics, 23(6), 573-578.

Burns, N., \& Grove, S. K. (2009). Chapter 14: Sampling. In The practice of nursing research: Appraisal, synthesis, and generation of evidence (p. 356). St. Louis, MO: Saunders/Elsevier.

Cluett, J., M.D. (2014). Anterior Cruciate Ligament - ACL. Retrieved from http://orthopedics.about.com/cs/aclrepain/g/acl.htm

Diaz, A., MD. (2014). Anterior Cruciate Ligament (ACL) Reconstruction, Danbury Connecticut. Retrieved from http://www.albertdiazmd.com/acl-reconstruction.html

Diseases and Conditions ACL injury Definition. (2013). Retrieved from http://www.mayoclinic.org/diseases-conditions/acl-injury/basics/definition/con-20030106 
Feller, J. A., \& Webster, K. E. (2003). A randomised comparison of patellar tendon and hamstring tendon anterior cruciate ligament reconstruction. American Journal of Sports Medicine, 31, 564-574.

Fischer, S. J., MD, PhD, \& Campbell, B. J., MD (Eds.). (2014, March). Anterior Cruciate Ligament (ACL) Injuries. Retrieved from http://orthoinfo.aaos.org/topic.cfm?topic=a 00549

Fleming, B.C. (2003). Biomechanics of the anterior cruciate ligament. J Orthop Sports Phys Ther 33:A13-A15

Hudes, K. (2011). The Tampa Scale of Kinesiophobia and neck pain, disability and range of motion; a narrative review of the literature. Journal Of The Canadian Chiropractic Association, 55(3), 222-232.

Johnston, L. H., \& Carroll, D. (1998). The context of emotional responses to athletic injury: A qualitative analysis. Journal of Sport Rehabilitation, 7, 206-220.

Krosshaug, T., Nakamae, A., Boden, B. P., Engebretsen, L., Smith, G., Slauterbeck, J. R., . . . Bahr, R. (2007). Mechanisms of anterior cruciate ligament injury in basketball: Video analysis of 39 cases. The American Journal of Sports Medicine, 35(3), 359-367.

Kvist, J., Ek, A., Sporrstedt, K., \& Good, L. (2005). Fear of re-injury: A hindrance for returning to sports after anterior cruciate ligament reconstruction. Knee Surgery Sports Traumatology Athroscopy, 13, 393-397.

Kvist, J. J., Österberg, A. A., Gauffin, H. H., Tagesson, S. S., Webster, K. K., \& Ardern, C. C. (2013). Translation and measurement properties of the Swedish version of ACL-Return to Sports after Injury questionnaire. Scandinavian Journal Of Medicine \& Science In Sports, 23(5), 568-575. 
Langford, J.L. (2009). A prospective longitudinal study to assess psychological changes following anterior cruciate ligament reconstruction surgery. British Journal Of Sports Medicine, 43(5), 377-378.

Mainwaring L. (1999). Restoration of self: A model for psychological response of athletes to severe knee injuries. Can J Rehab. 12: 145-56

Myer, G. D., Ford, K. R., Brent, J. L., \& Hewett, T. E. (2007). Differential neuromuscular training effects on ACL injury risk factors in "high-risk" versus "low-risk" athletes. BMC Musculoskeletal Disorders, 8, 39 .

Olofsson, L., Fjellman-Wiklund, A., \& Soderman, K. (2010). From loss towards restoration: Experiences from anterior cruciate ligament injury. Advances in Physiotherapy, 12, 5057. doi: $10.3109 / 14038190903165120$

Peterson, J., \& Peterson, E. (2012). Anterior cruciate ligament injury in the athlete-an update in prevention strategies. South Dakota Medicine: The Journal of the South Dakota State Medical Association, 65(11), 421.

Podlog, L., \& Eklund, R. C. (2007). The psychological aspects of a return to sport following serious injury: A review of the literature from a self-determination perspective. Psychology of Sport and Exercise, 8, 535-566.

Porucznik, M. A. (2013). Study Takes Close Look at Impact of ACL Surgery. American Academy of Orthopaedic Surgeons. Retrieved from http://www.aaos.org/news/aaosnow/n ov13/cover1.asp

Quinn, E. (2014, June 10). ACL. Retrieved from http://sportsmedicine.about.com/od/glossary/g/ ACL_def.htm

Samuelsson, K. (2012). Anatomic anterior cruciate ligament reconstruction - current evidence nd 
future directions.

Simon, R. A., Everhart, J. S., Nagaraja, H. N., \& Chaudhari, A. M. (2010). A case- control study of anterior cruciate ligament volume, tibial plateau slopes and intercondylar notch dimensions in ACL-injured knees. Journal of Biomechanics, 43(9), 1702-1707.

Stijak, L., Herzog, R. F., \& Schai, P. (2008). Is there an influence of the tibial slope of the lateral condyle on the ACL lesion? A case-control study. Knee Surgery, Sports Traumatology, Arthroscopy, 16(2), 112-117.

Thomee, P.P., Wahrborg, P.P., Borjesson, M. M., Thomee, R. R., Eriksson, B. I., \& Karlsson, J. J. (2006). A new instrument for measuring self-efficacy in patients with an anterior cruciate ligament injury. Scandinavian Journal of Medicine \& Science In Sports, 16(3), 181-187,

Tripp, D., Ebel-Lam, A., Birchard, J., Stanish, W., \& Brewer, B. (2007). Fear of reinjury, negative affect, and catastrophizing predicting return to sport in recreational athletes with anterior cruciate ligament injuries at 1 year postsurgery. Rehabilitation Psychology, 5

Webster, K., Feller, J., \& Lambros, C. (2008). Development and preliminary validation of a scale to measure the psychological impact of returning to sport following anterior cruciate ligament reconstruction surgery. Physical Therapy In Sport, 9(1), 9-15. 


\section{APPENDIX A \\ Permission email from Dr. Kate Webster to use the ACL-RSI}

Hi Molly,

Please find the ACL-RSI scale questions attached.

I should note that the response format slightly differs between our papers. The original scale (as published in Webster et al 2008) was scored using a 10cm VAS. However, we found that it was rather time consuming to score a VAS and we wanted the scale to be as simple as possible so it could be potentially used clinically. Therefore, for the Langford paper we changed the VAS line to a tick in the box format, still with a 0 to 100 range but with 10 point increments. For the total scale score the answers are simply summed and averaged. Attached is the version we used for the Langford paper. Please note that we have not formally compared changing from a VAS to a tick in the box version. If you prefer to use a VAS the boxes are to be replaced with a $10 \mathrm{~cm}$ linethe same end descriptors are used.

All the best for your research.

Kate

Kate Webster Ph.D.

Associate Professor

Faculty of Health Sciences, La Trobe University

Bundoora, Vic, 3086, Australia 


\section{APPENDIX B \\ Recruitment email approved by CU IRB}

Hello (participants name),

My name is Moriah Frazee. My sister and I are both nurses and current nurse practitioner students at Cedarville University in Ohio. We are writing to invite you to participate in a study to measure the emotional impact of ACL injury. We have both torn our Anterior Cruciate Ligaments playing basketball in college so this topic is of both personal and professional interest to us.

If you are between the ages of 18-40 and are willing to participate, please click on the link below. All the information we collect is completely anonymous and your name will not be linked to any data. When we report the results, we will report aggregate data only.

This survey contains 22 questions, and once you start, you are still free to stop the survey and withdraw at any time.

Thank you so much for your consideration. If you have any questions or concerns you can reply to the following email addresses: mmfrazee@cedarville.edu or mfrazee@cedarville.edu.

Thanks,

Moriah and Molly Frazee 


\section{APPENDIX C \\ Demographic and Intention questions on the survey}

Please answer the demographic data below before completing the ACL-RSI scale:

1. Have you torn your ACL and undergone a surgical repair?

Yes No

2. Number of ACL injuries with repair?

One Two or more

3. What is your gender?

Female Male

4. What is your age?

5. How many years ago did you tear your ACL (the first time if more than one injury)?

6. What was your primary sport of participation before ACL Injury?

7. What was your level of participation in your sport before your ACL injury?

8. If you are currently in rehabilitation, answer this question based on how you feel now. If you have finished rehabilitation, answer this question based on how you felt during your rehabilitation.

Do you intend to return to your previous level of sport participation after your rehab is complete?

For example, if you started college level basketball before your injury, did you start college level basketball after your injury?

Yes No

9. Have you received full medical clearance to participate in your pre-injury level of sport?

Yes

No

10. Did you return to your previous level of sport participation after your ACL injury and surgical repair?

For example, if you started college level basketball before your injury, did you start college level basketball after your injury.

Yes No 
